\title{
Aspectos neurológicos del púrpura trombótico trombocitopénico: Presentación de un caso
}

\author{
Carolina Delgado $D^{1}$, Claudio Flores $\mathbf{P}^{2}$, Carlos Silva $\mathbf{R}^{1}$. \\ Thrombotic thrombocytopenic purpura \\ with neurological involvement \\ Report of one case
}

Neurological manifestations, secondary to perfusion problems, vasogenic edema or small infarcts, are common in thrombotic purpura. Moreover, they are the first symptoms of the disease in $50 \%$ of patients. We report a 50 year-old woman who presented with focal intermittent neurological signs with aphasia and right hemiparesis, who then developed progressive impairment of consciousness with stupor and generalized tonic-clonic seizures. Despite the severe neurological impairment, first neuroimaging studies were normal. A second magnetic resonance imaging showed small cortical infarcts, that were visible only with the technique of diffusion weighted imaging. The standard electroencephalograms showed focal left temporal slowing and low voltage first and then diffuse slowing accordind to the clinical condition of the patients. She was treated with plasmapheresis and had a partial neurological recovery at the fifth day, but died at the twelfth day of therapy (Rev Méd Chile 2006; 134: 348-52).

(Key words: Brain infarction; Magnetic resonance imaging; Purpura, thrombocytopenic)

Recibido el 11 de mayo, 2005. Aceptado el 8 de septiembre, 2005.

${ }^{1}$ Departamento de Neurología y Neurocirugía, Hospital Clínico Universidad de Chile. ${ }^{2}$ Departamento de Hematología, Hospital Clínico Universidad de Chile.

\begin{abstract}
A pesar de ser muy infrecuente, el púrpura trombótico trombocitopénico (PTT) debe tenerse presente como diagnóstico diferencial entre los casos de compromiso neurológico fluctuante y progresivo sin causa aparente, sobre todo en casos en que, a pesar de la severidad del compromiso neurológico, descartada la comicialidad, las neuroimágenes sean normales. Actualmente existen terapias efectivas que, de realizarse en forma precoz, reducen su mortalidad notablemente y revierten completamente los síntomas neurológicos en la mayoría de los casos.
\end{abstract}

Correspondencia a: Carolina Delgado Derio. Itata 4251, Ñuñoa, Santiago. Fax: 6789045. E mail: cdelgado@med.uchile.cl
Esta patología, conocida también como enfermedad de Moschowitz, quien la describió en 1926, se caracteriza por la péntada de: anemia hemolítica microangiopática, trombocitopenia, compromiso neurológico, falla renal y fiebre. Debe notarse que es frecuente la presentación incompleta, faltando alguno de estos elementos. Su prevalencia estimada en Estados Unidos de Norteamérica (USA) es de 3,7 casos/millón, afectando a ambos sexos y todas las edades, pero con preferencia por las mujeres en edad fértil. Antes de descubrirse la utilidad de la plasmaféresis y aporte de plasma fresco como terapia, la mortalidad superaba el $90 \%$, siendo actualmente menor a 30\% ${ }^{1}$. En cuanto a su etiopatogenia, en el PTT existe un déficit o menor actividad 
de una enzima dependiente de cobre y zinc que corta multímeros ultra grandes de factor von Willebrand ( $\mathrm{FVW}$ ), la metaloproteinasa ADAMTS13. En ausencia de esta proteinasa, quedan expuestos multímeros inusualmente grandes de fVW, secretados por las células endoteliales, que favorecen la adhesión plaquetaria patológica con la posterior activación, agregación y formación de trombos plaquetarios pobres en fibrina. Estos se desprenden y ocluyen en forma intermitente la microvasculatura, causando isquemia tisular sistémica, con preferencia por el sistema nervioso central, trombocitopenia por consumo y anemia hemolítica por lesión mecánica del glóbulo rojo ${ }^{2}$. El déficit de esta enzima puede ser congénito o, más frecuentemente, adquirido. En el segundo caso, lo más habitual sería una inactivación autoinmune por anticuerpos, que se forman en una persona predispuesta ante ciertos gatillantes; cuando éstos no se encuentran, se cataloga como cuadro idiopático ${ }^{3}$ (Tabla 1).

El diagnóstico es clínico, basado en compromiso neurológico fluctuante, síndrome purpúrico, fiebre, ictericia, hepatoesplenomegalia leve, insuficiencia renal, sumado al laboratorio característico (Tabla 2). La medición de la actividad de la metaloproteinasa es muy útil en casos dudosos, pero debe recalcarse que la espera de este resultado no debe retardar el inicio de la terapia si la sospecha clínica es fuerte, en presencia de alguna de las manifestaciones clínicas, hemólisis traumática, trombocitopenia, en ausencia de coagulación intravascular diseminada.

El tratamiento es con plasmaféresis (PF) diaria, la que removería estos multímeros de gran tamaño de fVW y los anticuerpos patogénicos, sumado a la transfusión de plasma fresco congelado (PFC)

\section{Tabla 1. C ausas de púrpura trombótico trombocitopénico}

- Idiopático

- Familiar

- Infección: HIV, E Coli

- Enfermedades del tejido conectivo: LES, ESP

- Embarazo y puerperio

- Neoplasia

- Quimioterapia: mitomicina, cisplatino

- Fármaco: ticlopidina, clopidrogel, quinidina, ciclosporina

- Trasplante de médula ósea que aportaría la metaloproteinasa. En algunos casos se agregan inmunodepresores como bolos de metilprednisolona, vincristina, anticuerpos monoclonales anti CD 20 y otros, si resulta refractario a las medidas señaladas más arriba ${ }^{1,3}$.

\section{Caso clínico}

Mujer chilena de 58 años con antecedentes de anemia y hematuria de 6 años de evolución, con diagnóstico de enfermedad de Berger en control con nefrólogo, sin antecedentes de uso de fármacos. Una semana previa a su evaluación médica empezó con cefalea, alteraciones en el lenguaje y falta de fuerza en la extremidad superior derecha de carácter fluctuante.

En el examen neurológico destacaba: una paciente vigil, orientada parcialmente, con la atención disminuida, lenguaje fluente con parafasias ocasionales, nominación, repetición, comprensión y lectoescritura alteradas. En el examen motor destacaba una prueba de pequeña paresia con leve pronación de la extremidad superior derecha y reflejo plantar indiferente a derecha. El resto de la evaluación era normal.

Se hospitalizó con los diagnósticos de: accidente cerebrovascular agudo silviano izquierdo, afasia de Wernicke, hemiparesia derecha de predominio braquial.

Se inició el estudio con una tomografía computada de cerebro (TC) y una difusión por resonancia nuclear magnética (RNM) que no mostraron lesiones isquémicas. Se realizó un electroencefalograma (EEG) estándar, que mostró una lentitud focal thetadelta temporal izquierda sin actividad epileptiforme

\section{Tabla 2. Características en el laboratorio del PT T}

- Anemia hemolítica microangiopática: Esquistocitos abundantes Reticulocitosis

Aumento de la bilirrubina indirecta Test de Coombs negativo

- Trombocitopenia, usualmente $<50.000 / \mu \mathrm{L}$

- Pruebas de coagulación normales

- Aumento de la lactato deshidrogenada

- Creatininemia variable

- Metalproteinasa $<5 \%$ 
(Figura 1A). Dentro de los exámenes sanguíneos destacaban unas pruebas de coagulación normal, anemia severa de características hemolíticas y trombocitopenia (Tabla 3).

La paciente evolucionó a las pocas horas de hospitalización con desorientación y agitación psicomotora. En el segundo día se agregó fiebre hasta 39,5 grados. En el examen neurológico destacaba: una paciente soporosa, con la mirada conjugada desviada a derecha, reflejos de tronco presentes. Ante el estímulo nociceptivo movilizaba y retiraba hemicuerpo derecho, con hipotonía del izquierdo y plantares indiferentes bilaterales.

Se realizó una nueva TC de cerebro que no mostró lesiones. Luego se realizó una difusión por RNM que mostró imágenes hiperintensas puntiformes cortico subcorticales bilaterales, compatibles con infartos agudos (Figura 2). Debido al severo compromiso de conciencia, pensando en un status epiléptico no convulsivo se realizó un segundo EEG estándar que mostró desorganización de la actividad basal, con marcada disminución de voltaje en las derivaciones derechas y lentitud temporal izquierda, sin actividad epileptiforme (Figura 1B).

En el laboratorio se constató acentuación de los indicadores de hemólisis con aumento de la bilirrubi- na indirecta y LHD, también aumento de la trombocitopenia y creatininemia. Se hizo el diagnóstico de PTT e inició tratamiento con plasmaféresis y transfusiones de plasma fresco congelado diariamente. Posteriormente se midió la actividad de la metaloproteinasa del fVW, que resultó $<5 \%$, el estudio de cáncer y mesenquemopatías fue negativo. La paciente evolucionó con episodios de convulsiones tonicoclónicas generalizadas, por lo que se agregó fenitoína. Al quinto día de tratamiento se evidenció una recuperación parcial del compromiso neurológico con vigilia espontánea, lenguaje escaso, no atingente, movilización del hemicuerpo derecho e hipotonía y paresia braquiocrural izquierda, con respuesta plantar extensora bilateral. Al sexto día de tratamiento nuevamente presentó fiebre y compromiso hemodinámico, con sepsis de foco pulmonar, se diagnóstico shock séptico e insuficiencia respiratoria severa, con necesidad de ventilación mecánica invasiva, uso de drogas vasoactivas y antibioterapia. Por la necesidad de sedación, se dificultó la evaluación neurológica posterior pero persistía con hipotonía del hemicuerpo izquierdo. La paciente falleció por falla multiorgánica a los 15 días de hospitalización y 13 de tratamiento con PF y transfusión de PFC, alcanzando a recibir tres bolos de metilprednisolona.

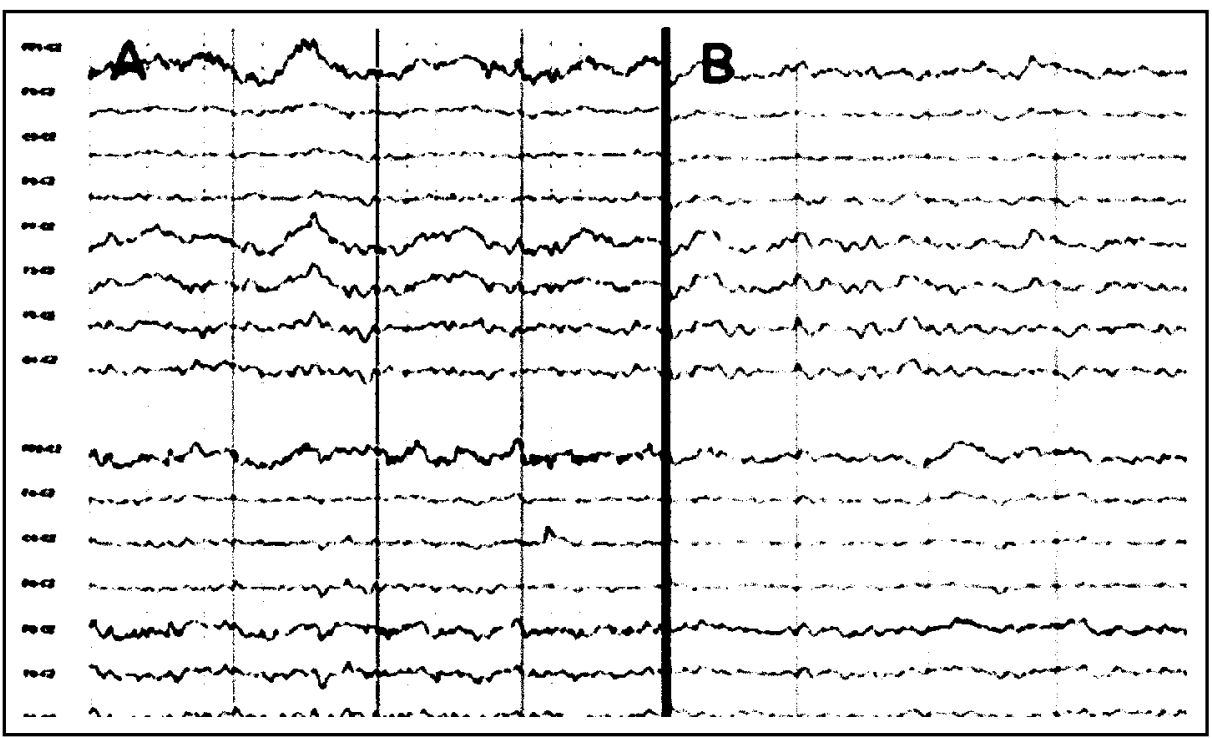

Figura 1. Electroencefalograma estándar, montaje monopolar a vertex. Las derivaciones superiores son las izquierdas y las inferiores derechas. A: día de ingreso, la paciente clínicamente presentaba afasia y hemiparesia derecha. Se observa un enlentecimiento de las frecuencias basales a nivel temporal izquierdo. B: segundo día, paciente en sopor profundo con hemiplejia izquierda. Se observa una desorganización de la base, con marcada disminución de la amplitud en el hemisferio derecho. 
Tabla 3. Evolución de los parámetros de laboratorio durante la hospitalización

\begin{tabular}{|lcccc|}
\hline & Día 1 & Día 2 & Día 5 & Día 15 \\
\hline Hematocrito & $17 \%$ & $24 \%$ & $22 \%$ & $23 \%$ \\
Hemoglobina & 5,9 & 8,4 & 7,9 & 8,5 \\
Bilirrubina total & 2,9 & 8,4 & 5,7 & 12 \\
Bilirrubina directa & & 1,66 & 2,9 & 8,23 \\
LDH & 945 & 1.616 & 903 & 3.182 \\
Plaquetas & 24.000 & 17.300 & 21.000 & 140.000 \\
Creatininemia & 0,73 & 1,28 & 0,8 & 2,17 \\
Tiempo de protrombina & $11 \mathrm{seg}$ & $14 \mathrm{seg}$ & & $(42 \%)$ \\
& $(93 \%)$ & $(65 \%)$ & & $28 \mathrm{seg}$ \\
TTPA & $28 \mathrm{seg}$ & $31 \mathrm{seg}$ & $<5 \%$ & \\
Metaloproteinasa & & & \\
\hline
\end{tabular}

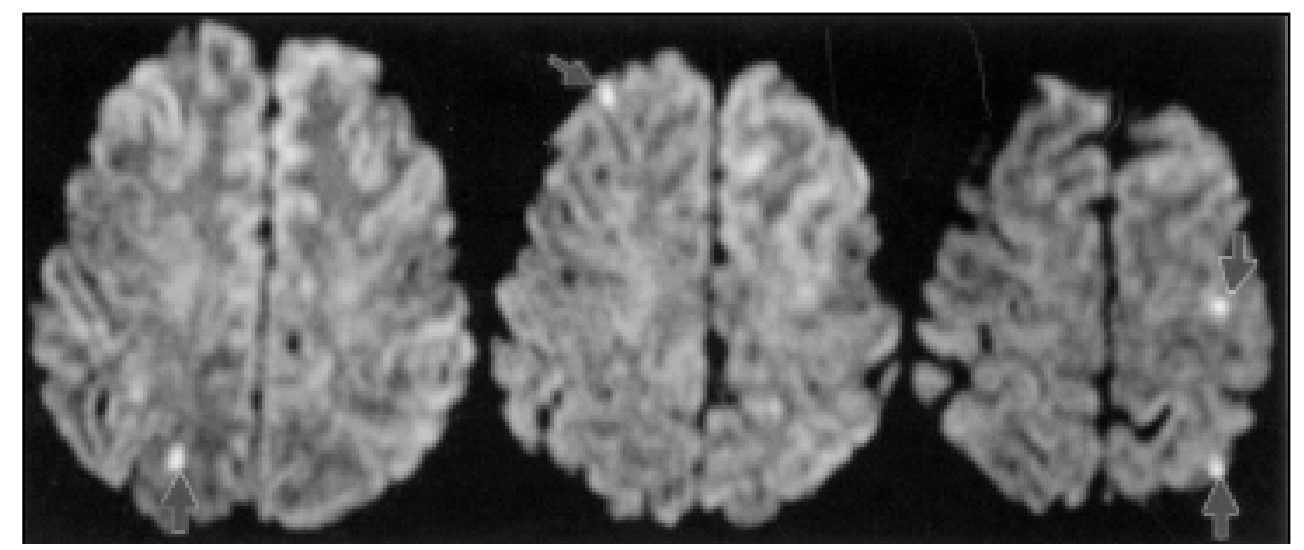

Figura 2. Secuencia de difusión por resonancia nuclear magnética de cerebro, cortes axiales. Segundo día de evolución: la paciente clínicamente estaba en sopor profundo con una hemiplejia izquierda. Se observan múltiples imágenes hiperintensas puntiformes corticales y subcorticales bilaterales, que corresponden a pequeños infartos en etapas agudas.

\section{DisCUSIÓN}

Más de 90\% de los casos de PTT tiene compromiso neurológico, siendo el síntoma de presentación en más de 60\%. Inicialmente son déficit neurológicos focales fluctuantes, alteraciones cualitativas de conciencia, incluso se describen alteraciones psiquiátricas $^{4,5}$. También durante la evolución son muy habituales las crisis convulsivas, con casos de status epiléptico no convulsivo como motivo del compromiso de conciencia ${ }^{6}$. La evolución natural es con progresiva disminución del nivel de conciencia llegando hasta el coma y la muerte. Dentro de esta evolución llama la atención la escasa alteración de las neuroimágenes anatómicas, siendo frecuente- mente la TC y RNM de cerebro normales. La recuperación neurológica puede ser total en el caso de una respuesta favorable a la $\mathrm{PF}^{4,7,8}$.

Se han postulado distintos mecanismos fisiopatológicos, el principal sería por hipoperfusión tisular cerebral, inicialmente focal intermitente y luego difusa, manteniendo a la corteza y áreas subcorticales en penumbra isquémica, alterándose la función de estas áreas, lo que explica los síntomas deficitarios y la disminución del nivel de conciencia. Esta hipótesis se ha validado con reportes en los cuales, estando los pacientes en coma con neuroimágenes anatómicas normales, estudios de perfusión con SPECT HM PAO muestra gran alteración en la perfusión cortical, que se normaliza una vez controlada la enfermedad ${ }^{5,9}$. Si 
esta hipoperfusión se mantiene pueden producirse infartos, generalmente de vaso pequeño, ubicados en la sustancia blanca subcortical y ganglios basales, sólo visibles precozmente con las técnicas de difusión por RNM. También se han publicado casos de infartos completos de arterias de mediano calibre como la arteria cerebral media ${ }^{10,11}$. Otro mecanismo participante sería el edema vasogénico secundario a alteraciones en la autorregulación endotelial por la isquemia. Hay reportes con imágenes compatibles con leucoencefalopatía posterior similar al encontrado en la encefalopatía hipertensiva, que revierte con el tratamiento sin dejar secuelas ${ }^{12}$.

En el caso presentado, a pesar de la afasia y hemiparesia derecha, las neuroimágenes iniciales fueron normales, mas el EEG mostraba lentitud focal izquierda. En la evolución, estando soporosa, la RNM sólo mostraba infartos puntiformes, con un EEG con marcada disminución de voltaje a derecha, desorganización y lentitud global. Hay reportes variables

\section{REFERENCIAS}

1. Elliott M, Nichols WI. Thrombotic Thrombocytopenic Purpura and Hemolytic Uremic Syndrome. Mayo Clin Proc 2001; 76: 1154-62.

2. George JN, Sadler Je, Lammle B. Platelets: thrombotic Thrombocytopenic purpura. Hematology Review (Am Soc Hematol Educ Program) 2002; 315-34.

3. Moake JL. Thrombotic microangiopathies. NEngl J Med 2002; 347: 589-600.

4. Kelly F, Treacher D, Williams F, Hunt B, Howard R. Coma in thrombotic thrombocytopenic Purpura. J Neurol Neurosurg Psychiatry 1999; 66: 688-97.

5. Baron $\mathrm{Y}$, Bargemann $\mathrm{T}$, Harten $\mathrm{P}$, Gutschmid $\mathrm{H}$. Thrombocytopenic thrombotic purpura: severe clinic with no CT, minor MRI, but a SPECT correlate. European J Radiol 1999; 31: 56-62.

6. Blum AS, Drislane FW. Nonconvulsive status epilepticus in thrombotic thrombocytopenic purpura. Neurology 1996: 47: 1079-81.

7. D'Aprile P, Farchi G, Pagliarulo R, Carella A. Thrombotic thrombocytopenic purpura. MR demonstration of reversible brain abnormalities. AJNR Am J Neuroradiol 1994; 5: 19-20.

8. Urushitani M, Seriu N, Udaka F, Kameyama M, Nishinaka K, Kodama M. MRI demonstration of a respecto a la utilidad del EEG en el compromiso neurológico del PTT, siendo algunos similares a nuestro caso en que reflejó fielmente la clínica y otros, dentro de ellos una serie de 16 pacientes, en que hubo poca relación del EEG con la clínica neurológica, salvo en los casos de comicialidad ${ }^{13}$.

Creemos interesante la presentación de este caso, como ejemplo de patologías médicas con compromiso neurológico secundario principalmente a hipoperfusión. Como ocurre también en vasculitis de vasos pequeños y durante el vasoespasmo inicial posterior a una hemorragia subaracnoidea, todos con neuroimágenes anatómicas iniciales normales, las imágenes funcionales como el SPECT o el PET evidencian mayor sensibilidad. Queremos destacar el rol del electroencefalograma estándar, que a pesar de su sensibilidad variable es de fácil y rápida realización y de un costo económico mucho menor al de los exámenes anteriores.

reversible lesion in cerebral deep white matter in thrombotic thrombocytopenic purpura. Neuroradiology 1996; 38: 137-8.

9. Fiorani L, Vianelli N, Gugliotta L, Vignatelli L, Corbelli C, D'Alessandro R. Brain MRI and SPECT in thrombotic thrombocytopenic purpura. Ital J Neurol Sci 1995; 16: 149-51.

10. Gruber O, Wittig L, Wiggins CJ, von Cramon DY. Thrombotic thrombocytopenic purpura: MRI demonstration of persistent small cerebral infarcts after clinical recovery. Neuroradiology 2000; 42: 616-8.

11. Kondo K, Yamawaki T, Nagatsuka K, Miyashita K, NARITOMI H. Reversible stenosis of major cerebral arteries demonstrated by MRA in thrombotic thrombocytopenic purpura. J Neurol 2003; 250: 995-7.

12. Bakshi R, Shaikh ZA, Bates VE, Kinkel PR. Thrombotic thrombocytopenic purpura: Brain CT and MRI findings in 12 patients. Neurology 1999; 52: 1285.

13. Meloni G, Proia A, Antonini G, De lena C, Guerrisi V, Capria S et al. Thrombotic thrombocytopenic purpura: prospective neurologic, neuroimaging and neurophysiologic evaluation. Haematologica 2001; 86: 1194-9. 